\title{
Explicit processing of verbal and spatial features during letter-location binding modulates oscillatory activity of a fronto-parietal network
}

\author{
Claudia Poch ${ }^{a, 1}$, Pablo Campo ${ }^{a, *, 1}$, Fabrice B.R. Parmentier ${ }^{b, c}$, José María Ruiz-Vargas ${ }^{d}$, Jane V. Elsley ${ }^{e}$, \\ Nazareth P. Castellanos ${ }^{a}$, Fernando Maestúa ${ }^{a, f}$, Francisco del Pozo ${ }^{a}$ \\ 'Laboratoly of Cognitive and Computational Neuroscience, Complutense University of Madrid-Polytechnic University of Madrid, 28040 Madid, Span \\ - Deparanent of Psychology, University of the Balearic islands, Spain \\ 'School of Psychology, University of Western Alistraila, Alistralia \\ d Department of Basic Psycholong, Alitonoma University of Madrid, Madrid, Spain \\ e School of Psychology, University of Bouluemouth, UK \\ 'Department of Basic. Psyciology Cognitive Processes II, Complatense University of Madizid, Madiad, Spain
}

\begin{abstract}
A B S T R A C T
The present study investigated the binding of verbal and spatial features in immediate memory. In a recent study, we demonstrated incidental and asymmetrical letter-location binding effects when participants attended to letter features (but not when they attended to location features) that were associated with greater oscillatory activity over prefrontal and posterior regions during the retention period. We were interested to investigate whether the patterns of brain activity associated with the incidental binding of letters and locations observed when only the verbal feature is attended differ from those reflecting the binding resulting from the controlled/explicit processing of both verbal and spatial features. To achieve this, neural activity was recorded using magnetoencephalography (MEG) while participants performed two working memory tasks. Both tasks were identical in terms of their perceptual characteristics and only differed with respect to the task instructions. One of the tasks required participants to process both letters and locations. In the other, participants were instructed to memorize only the letters, regardless of their location. Time-frequency representation of MEG data based on the wavelet transform of the signals was calculated on a single trial basis during the maintenance period of both tasks. Critically, despite equivalent behavioural binding effects in both tasks, single and dual feature encoding relied on different neuroanatomical and neural oscillatory correlates. We propose that enhanced activation of an anterior-posterior dorsal network observed in the task requiring the processing of both features reflects the necessity for allocating greater resources to intentionally process verbal and spatial features in this task.
\end{abstract}

The capacity to maintain and manipulate information in working memory (WM) is critical to higher cognitive functions. Despite its crucial role in a number of mental skills and abilities, WM capacity is surprisingly limited. Through the integration of individual features into "objects", however, we are capable of processing larger amounts of information. Indeed, recent experimentation suggests the limit of WM capacity to be set at around three to four bound "objects" (Cowan, 2001; Todd \& Marois, 2004; Vogel, Woodman, \& Luck, 2001). The ability to integrate information involves "the reorganization of bits of information to create more complex but unified representations of previously distributed information" (Wheeler \& Treisman, 2002), a phenomenon iden-

\footnotetext{
* Corresponding author. Tel.: +349] $5495700 ;$ fax: +34913366828.

E-mail addresses: Pcampo@arrakis.es, pcampo@med.ucm.es (P. Campo).

1 These authors contributed equally to the study.
}

tified in the memory literature as 'chunking' (Baddeley. 2000; Ericsson, Chase, \& Faloon, 1980; Miller, 1956; Simon, 1974). In visual WM, the integration of different stimulus features into more complex representations or objects is most often referred to as 'binding' (Alvarez \& Cavanagh, 2004; Bays \& Husain, 2008; Eriksen \& Yeh, 1985; Gray, 1999; O'Craven, Downing, \& Kanwisher, 1999; Wheeler \& Treisman, 2002; Wolfe et al., 1990), a process increasingly recognized as a critical determinant of memory performance (Cowan, 2001). A large part of the existing research on binding and WM has focused on the integration of visual features (Bodelon, Fallah, \& Reynolds, 2007; Filbey, Holroyd, Carver, Sunderland, \& Cohen, 2005; Friedman-Hill, Robertson, \& Treisman, 1995; luck \& Vogel, 1997; Todd \& Marois, 2004; Vogel \& Machizawa, 2004; Zhang \& Luck, 2008) and, to a smaller extent, auditory features (Maybery et al., 2009; Saito et al., 2005; Widmann, Gruber, Kujala, Tervaniemi, \& Schroger, 2007). The integration of (visually presented) verbal and spatial features has attracted, in comparison, 
less scrutiny. However, interest has recently grown following the addition to the WM model of the episodic buffer, a new component, defined as "an interface between a range of systems, each involving a different set of codes" (Baddeley, 2000). The inclusion of this component mainly responded to the initial model's limitations in accounting for the binding between representations handled by the WM's visual and verbal subsystems, or the links between long-term language knowledge and WM (Allen, Baddeley, \& Hitch. 2006). Recently, several behavioural studies have begun to investigate the mechanisms underpinning verbal-spatial binding (Cowan, Saults, \& Morey, 2006; Luck, Foucher, Offerlin-Meyer, Lepage, \& Danion, 2008; Mitroff \& Alvarez, 2007; Morey, 2009; Oberauer \& Vockenberg, 2009). The neural bases of this type of binding have also been investigated by means of functional magnetic resonance imaging (fMRI) and magneto/electroencephalography (MEG/EEG) (Campo et al., 2005, 2008, 2010; luck et al., 2010; Prabhakaran, Narayanan, Zhao, \& Gabrieli, 2000; Wu. Chen, Li, Han, \& Zhang, 2007). All of these studies used modified versions of the single probe change-detection task developed by Prabhakaran et al. $(2000)$, in which participants were asked to maintain both verbal (either letters or words) and spatial (locations) information presented either in an integrated (bound condition) or in an unintegrated fashion (separate condition). When contrasting bound and separate conditions, greater activations were typically found in anterior prefrontal cortex (PFC) in the former, suggesting a fundamental role of this region in the binding process. These results are in agreement with previous findings on object-location binding in animals (Rainer, Asaad, \& Miller, 1998a, 1998b; Rao, Rainer, \& Miller, 1997), and humans (Filbey et al., 2005; Mitchell, Johnson, Raye, \& D'Esposito, 2000; Simon-Thomas, Brodsky, Willing, Sinha, \& Knight, 2003). Additionally, greater involvement of posterior parietal cortex (PPC) during the maintenance of integrated verbal-spatial information has also been observed (Campo et al., 2005, 2008; Luck et al., 2010; Wu et al., 2007).

In a recent study (Campo et al., 2010), we demonstrated implicit verbal-spatial binding effects that were dependent on the task-relevant feature. We used MEG to measure brain activity underpinning the maintenance of verbal and spatial features in two recognition tasks, based on a letter-location paradigm previously used in binding studies (Prabhakaran et al., 2000). In both the verbal and spatial tasks, participants were presented with four consonants appearing simultaneously in four distinct locations. Both tasks were identical in terms of their perceptual characteristics and only differed with respect to the task instructions. In the verbal task. participants attended to the consonants only (their locations were irrelevant), while in the spatial task they attended to the locations only (consonants identity was irrelevant). We observed that maintaining the verbal information (consonants) arranged in a spatially distributed manner resulted in the concurrent processing of the (task-irrelevant) location information-in other words, attending to consonant identity resulted in binding those consonants to their spatial locations. Interestingly, the reverse effect was not observed, supporting the notion of an asymmetric association between verbal and spatial features. This implicit or unintentional binding of verbal and spatial features was associated with greater oscillatory activity over PFC in "classical" frequency bands during the first half of the retention period and accompanied by greater activity in PPC and temporal regions.

Despite the fact that the processing of the spatial feature occurred in an involuntary manner, the pattern of brain activation was very similar to that observed in previous studies in which participants attended to, and intended to maintain, both verbal and spatial features (Campo et al., 2005, 2008; Luck et al., 2010; Prabhakaran et al., 2000; Wu et al., 2007). This similarity is intriguing considering evidence from neuroimaging studies establishing distinct neuroanatomical substrates for controlled and inciden- tal memory (Chiu et al., 2006; Dove, Manly, Epstein, \& Owen, 2008: Fletcher et al., 2001; Lekeu et al., 2002; Noldy. Stelmack, \& Campbell, 1990; Reber, Gitelman, Parrish, \& Mesulam, 2003; Reber et al., 2002; Rugg, Fletcher, Frith, Frackowiak, \& Dolan, 1997; Rugg et al., 1998; Russeler, Hennighausen, Munte, \& Rosler, 2003; Schott, Richardson-Klavehn, Heinze, \& Duzel, 2002; Schott et al., 2005). Brain areas showing greater responses in the controlled memory commonly include anterior PFC and posterior cerebral regions. Executive processes related to voluntary cognitive processing of information have been related to anterior PFC (Bor, Duncan, Wiseman, \& Owen, 2003: Buckner \& Koutstaal, 1998; Dove et al., 2008; Fernandez \& Tendolkar, 2001; Wagner, 1999), while stimuljspecific enhanced activity in posterior areas has been suggested to be the result of frontally guided control processes (Dove et al., 2008).

We were interested to investigate whether the patterns of brain activity associated with the incidental binding of letters and locations observed when only the verbal feature is attended (Campo et al., 2010) differ from those reflecting the binding resulting from the controlled/explicit processing of both verbal and spatial features. To this end, we used MEG to compare the neural oscillatory activity occurring in two tasks: one in which participants attended to the verbal features only, and one in which both letters and locations were intentionally processed. As recently highlighted by Voss and Paller (Voss \& Paller, 2008), it is important to use similar memory tests and procedures in order to determine "the extent to which certain neural processing events uniquely contribute to only one type of memory". Therefore, in line with our previous study, both tasks were identical in terms of their perceptual characteristics (participants were presented with four consonants appearing simultaneously in four distinct locations) and only differed with respect to the task instructions. One of the tasks required participants to encode both letters and locations, while in the other participants were instructed to memorize the letters only, regardless of their location. The presence of binding was measured behaviourally by comparing performance in two critical types of positive recognition probes: intact and re-combined probes. Intact probes consisted of a letter presented in the same location as at encoding. Re-combined probes involved a letter and location both presented at encoding but not together (i.e. a letter and location switch). As both probe types were identical in terms of their constituent features and only differed with respect to their original pairing (preserved or swapped), an advantage of recognizing intact over re-combined probes, in accuracy and/or reaction time (RT), would indicate that verbal and spatial features were maintained in an integrated fashion in WM. In contrast, if verbal and spatial features were held independently, intact and re-combined probes would be functionally equivalent and would yield similar levels of performance. Our rationale follows the so-called objectspecific repetition effect. first described by Kahneman, Treisman, and Gibbs (1992), according to which the processing of a visual item is facilitated by its repetition as long as the relationship between visual identity and spatial location is maintained across repetitions (Elsley \& Parmentier, 2009, see also Prabhakaran et al., 2000).

As binding was anticipated in both tasks, of interest was the pattern of neural activity in each based on the instruction relating to spatial location. In other words, would activations differ based on whether the encoding of spatial location was implicit (the verbal only task) or intentional (the verbal-spatial task)? Considering previous evidence (Kubler, Murphy, Kaufman, Stein, \& Garavan, 2003), we hypothesized that the explicit requirement of processing both verbal and spatial features would impose greater demands, and that, accordingly, additional executive functions will be necessary. Therefore, we expected that greater engagement of strategic control processes would be associated with a greater neuronal 


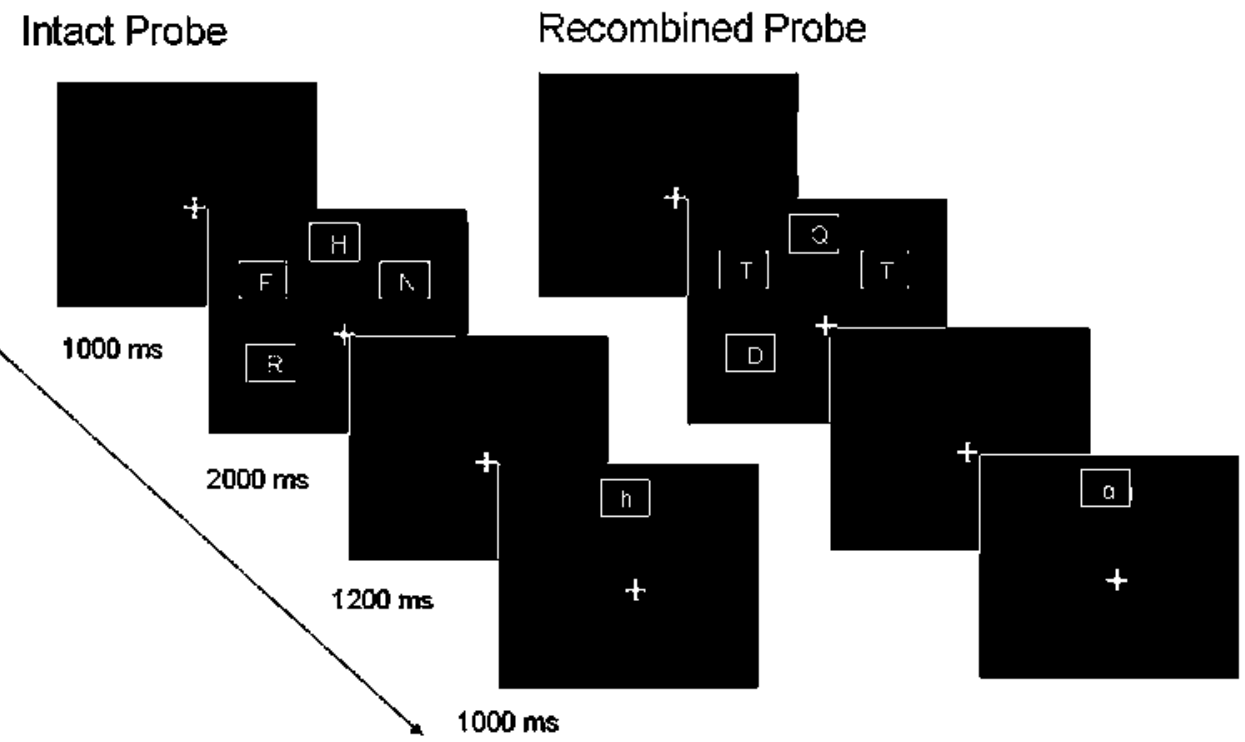

Fig. 1. Schematic illust ration of both types of positive recognition probes. Trials in the verbal and verbal-spatial conditions were identical and differed only with respect to the instructions given to participants (to memorize either the consonants, regardless of their location, or both the consonants and the locations). The examples depicted on this figure are that of an intact probe (a letter that was in location) and recombined probe (both consonant and location wete presented in the to-be-remembered artay but not together). Probe consonants were always in lower case form.

oscillatory activity in various frequency bands, predominantly in the anterior $\mathrm{PFC}$, and possibly also affecting oscillatory activity of posterior brain systems.

\section{Materials and methods}

\subsection{Subjects}

Elevell adult subjects (6 temales), ayed between 22 and 32 (meall aye 24,36 years, SD of 2.99 years) participated in the present study. These participants had no history of neurological or psychiat ric illness and had participated in our previous study (Campo et al., 2010). All gave their written consent, in accordance with the Declaration of Helsinki, after receiving a full briefing regarding the nature of the procedures involved in the experiment. They received $40 \in$ upon completion of the experiment.

\subsection{Stimutl and tosks}

Experimental tasks were modelled on a letter-location paradigm developed by Prabliakaran et al. (2000) and adapted by Elsley and Parmentier (2009) consisting of a visual me mory array of four consonants displayed in tour locat ions (Fig. 1). The verbal stimuli comptised a set of eight consonants (atial tont: $48 \mathrm{pt}$ ), selected so as to differ in appearance between upper- and lower-case forms (D, F, H, J, N, O, R, T) The spatial stimuli were presented within a set of eight spatial locations, marked by squares, placed equidistantly in a circular manner and sustaining a visual angle of $3^{\prime} 63^{\circ}$ from the center of each square to the central fixation cross. Both tasks used identical stimuli, but diftered with respect to the features to be attended and memorized, In the verbal task, participants were asked to remember the identity of the consonants, irrespective of their location. In the verbal-spatial task, participants wete instructed to remember both the identity and the location of the consonants. Each task began with a self-paced set of instructions, and five practice trials. At the beginning of eachtrial, participants first 5 aw a 500 ms cent ral fixation cross, followed by a sample memory array consisting of four consonants, dis played in white (against a black background) and in upper-case, selected at random (without replacement) from the above set of eight. Eacli consonant appeared in a distinct location randomly selected (without replacement) trom the possible set of eight. The consonants were presented within a $187^{\circ}, 187^{\circ}$ white trame to reduce variations in spatial configuration caused by the consonants perse (Delvenne, Braithwaite, \& Humphreys, 2002) The to-be-remembered array remained on the $5 c r e e n$ for $2000 \mathrm{~ms}$. After a $1200 \mathrm{~ms}$ delay interval, in both tasks, participants were presented with a single lower-case consonant in a location for $1000 \mathrm{~ms}$, during which they were required to respond (a $1000 \mathrm{~ms}$ blank screen followed this response period betore the onset of the mext trial).

The task in the vetbal condition was to indicate, by button press, whether the probe consonant was part of the to-be-temembered array, regardless of its location. In the veゆal-5patial task, participants were required to decide whether both the probe consonant and location appeared in the to-be-remembered display (regardless of whether these consonant and locations had been presented together). Two types of c ritical pos itive-recognition probes (requiring a "yes" response) were presented constituting our measure of binding: intact and re-combined probes. Intact probes consisted of a letter presented in the same location as at encoding. Recombined probes involved a letter and location both presented at encoding but not together (i.e. a letter and location switch). The negat ive recongition probes (requiring a "no" response) were as follows: a new consonant in a new location (in the verbal task only); an old location occupied by a new consonant (in both the verbal and the verbal-spatial tasks); and an old consonant in a new location (in the verbal-spatial task only). In both tasks, instnictions emphasized the importance of both accuracy and speed.

\subsection{Procedures}

MEG scans we re obtained during the vemal and the vebal-spatial tasks. A total of 480 trials were presented in each task. Experimental conditions were completed in different sessions lasting $45 \mathrm{~min}$ approximately. Tasks were purpose-written using E-prime (Sclineider, Escliman, \& Zuccoloto, 2002).

The stimuli were projected through a LCD video-ptojector (SONY VPL-X600E) situated outside the shielded room on-to a series of in-room mirrors, the last of which was suspended approximately 60 ( $m$ above the subject's face $\left(19^{\prime} 8^{\prime} \backslash 26^{\prime} 1^{\prime}\right)$

\subsection{Data collecton and anarysis}

All MEG recordings were carried out using a whole-head neuromagnetometer containing an array of 148 magnetometers (4-D WHS 2500\%, San Diego) and situated in a magnetically shielded room. The data were collected using a sample rate of $254 \mathrm{~Hz}$ and band pass filtered between 0.1 and $50 \mathrm{~Hz}$. MEG data wete submitted to an interactive noise reduction procedure that helped reduce environmental moise as part of the signal analysis package. Ventical and horizontal bipolar electro-oculograms (EOG) were also recorded by bipolar mont ages using a Synamps amplifier (NeuroScan, El Paso, Texas) with Ag/AgClelectrodes (same sample rate and online filters as mentioned previously). Trials containing eye movement or blinks (as indicated by peak-to-peak amplitudes in the Eocic hannels in excess of $50 \mu \mathrm{V}$ ) or other myogenic or mechanical attitacts were removed using the automated artifact rejection algoritlm implemented in the Brain Electrical Source Analys is softwate suite (BESA 5.1: Megis Softwate). Analyses were limited to the retention period of trials in which participants responded correctly (hits and correct rejections), as our aim was to examine the maintenance of information in WM

Time-frequency (TF) representation of MEG data based on the wavelet transform of the signals (Mallat, 1998; Tallon-Baudry, Bertrand, Delpuech, Permier 1997) was calculated on a single trial basis for a $1700 \mathrm{~ms}$ time window starting from $500 \mathrm{~ms}$ before the onset of the stimulus presentation, and $1200 \mathrm{~ms}$ starting from the beginning of maintenance period. Wavelet transtorm is a dynamical alternative to Fourier, used to pertorm time spectral analyses for non-stationary time series. The continuous wavelet transform (WT) of a signal x(t) (MEG recordings in our case) suppose its projection onto a set of basic functions obtained from mother wavelet $\psi^{\prime}$ by rescaling and translating it along the time axis. Wavelet coefficients 
of the $x(t)$ signal in the time-spectral plane $(p, z), W(p, z)$, were obtained as follows:

$W(p, z)=\frac{1}{\sqrt{p}} \int_{-\infty}^{\infty} x(t) \Psi^{*}\left(\frac{t-z}{p}\right) d t$

where parameters $z$ and $p$ play the role of localization and petiod of the rhyt limic component, respectively. To study rhythmic components of a signal the Morlet wavelet mother function is well suited:

$\Psi(v)=\exp (j 2 \pi) \exp \left(\frac{-y^{2}}{2 k_{0}^{2}}\right)$

where $k_{0}$ is a parameter that can be chosen according to the research aim, in this case we set to 10 .

Dipolar magnetometer topographies are difficult to interpret with respect to the underlying generator sources. The mixing of 5 ignals from different sources in a single sensor, as well as artificial interactions generated by two sensors picking up a signal trom a single source are probable causes of contound (Fan et al., 2007: Palva, Monto. \& Palva, 2010). Accordingly, we decided to model frequency changes in the soutce space (Palva et al., 2010). The minimum-norm estimat ion procedure (MNE) was used to pertorm the sou rce localization of the TF MEG signals cortesponding to the retention period neuronal response. A tessellated cortical mesh tem plate surface derived from the Montreal Neurological Inst itute (MNI) phantom brain and implemented in SPM5 (http:/fwww.fil.ion.ucl.ac.uk/spm/software/spm5/) served as a brain model to est imate the current source distribution. This MNI dipole mesh (3004 nodes) was used to calculate the forward solution using a head model based on ovetlapping local spheres (Huang, Moshet; \& Lealy, 1999). The inverse solution was calculated by applying 12 MNE, with standard Tikhonov regularization, implemented in BrainStorm (http:/fneuroimage.usc.edu/brainstorm/). Tikhonov regularization is needed to control for the effect of the noise on the solution (Bouhamidi s Jbilou, 2007). Jensen and Vanni $(2002)$ have demonstrated that by transforming the real and imaginary parts of the Fourier components in the source domain by means of MNE and combining them it is possible to identify source areas of rhythmic activity in the trequency domain. Accordingly, in our study the underlying current source density (the sou rce strengtl at each node of the MNI phantom brain) of four frequency bands (theta, 4-8 Hz: alpha, 8-12 Hz; beta, 13-30 Hz: gamma, 30-50 Hz) was estimated by calculating the MNE in the frequency domain (Jensen \& Vanni, 2002: Moratti, Rubio, Campo, Keil, \& ortiz, 2008). Here, the real and imaginary parts of each wavelet component averaged within each of the four frequency bands was submitted to the MNE analysis. Thereafter, the MNEs of the real and imaginary parts were combined by using the root square of the sum of squares of the two wavelet patts as an estimate of absolute amplitude. The change in amplitude was calculated witl tespect to a baseline period before the beyinning of eacli epocli. For each frequency band. the mean time-frequency amplitude of the prestimulus period (between 500 and oms before stimulus onset) was considered as a baseline and subtracted from the time-frequency represent ation in order to normalize it. In order to exclude baseline differences between conditions a baseline comparison was performed. No significant differences were tound in this pre-stimulus period of time. The amplitude values at each dipole location of the brain surface mesh cortesponding to the TFvalues were statistically analyzed by using a Student $t$-tests to compare the verbal and verbal-spatial conditions. A nomparametric permutation test was conducted to explore differences in brain activity (Maris \& Oostenveld, 2007). This test controls for the false alarms in a situation involving multiple comparisons. MNE source strength values were shuffled within each condition (verbal and verbal-5patial) under the null hypothes is of no differences between them. The statistic employed in the permutation test was the maximum statistical value accoss time and fiequency dimensions. 511 permutations were computed in which condition labels (verbal and vetbal-spatial) were randomly assigned to data sets from both groups. For each source, the p-value was approximated by a Monte Carlo estimate and calculated according to the proportion of the permutation dist ribution exceeding the observed maximum source test statistic. Sources exceeding a corrected p-value of .05 were considered significant. Given that the corrected values are very conservative, we also present significant differences in activated brain regions (cortected) at more a liberal threshold ( $p<.001$, uncortected) for the purposes of describing the timing of activation.

\section{Results}

\subsection{Behavioural data}

Data from two participants containing MEG signals with noise levels that prevented further analysis data were excluded from behavioural and $T-F$ analysis. Performance was assessed in terms of accuracy (\% correct) and reaction time (RT), for correct responses, for both positive probe trials (intact and recombined) in each task.

We conducted separate repeated-measures analysis of variance (ANOVA) for accuracy and for RT measures. The ANOVAs con- tained two within-subjects factors, task (verbal vs. verbal-spatial), and probe type (intact vs. recombined). Greater accuracy on intact probes $(M=90.16 \% ; S D=9.26$ for the verbal task; $M=87.56 \%$; $S D=7.56$ for the verbal-spatial task) than on recombined probes $(M=84.01 \% ; S D=7.17$ for the verbal task; $M=83.39 \% ; S D=7.82$ for the verbal-spatial task) led to a significant main effect of probe-type $(F(1,8)=24.54 ; p<.001)$. No significant effect of task $(F(1,8)=.16 ; p>.60)$, nor task by probe type interaction $(F(1,8)=.172 ; p>.40)$ were found. Participants were faster on intact probes $(M=906.22 \mathrm{~ms}$; $S D=181.86$ for the verbal task; intact: $M=956.33 \mathrm{~ms} ; S D=204.90$ for the verbal-spatial task) compared to recombined probes $(M=927.78 \mathrm{~ms} ; S D=175.7$ for the verbal task; $M=989.67 \mathrm{~ms} ; S D=224.85$ for the verbal-spatial task) as indicated by a main effect of probe-type $(F(1,8)=9.85 ; p<.02)$. Neither the main effect of task nor the interaction approached significance $(F(1,8)=1.43 ; p>.20 ; F(1,8)=.83 ; p>.30$, respectively $)$.

Thus, statistical analyses of our behavioural data indicated that significant and equivalent verbal-spatial binding effects were observed in both tasks. Having established the existence of binding in both tasks at the behavioural level, we proceeded to compare the source localization of oscillatory activity between the two tasks.

\subsection{Distributed source localization and time course of oscillatory activity during the maintenance period}

\subsubsection{Theta frequency band $(4-8 \mathrm{~Hz})$}

Significant differences indicating greater activation during the verbal-spatial task were observed in premotor areas. Source amplitudes were greater in the verbal-spatial task compared to the verbal task in right premotor area, reaching their maximum at around $220 \mathrm{~ms}$ ( $p<.05$, corrected). Using an uncorrected $p$ value of .001 , we observed that this activity lasted from $170 \mathrm{~ms}$ to $300 \mathrm{~ms}$ post-stimulus offset. Left premotor area also showed greater activity during the verbal-spatial task, reaching its peak at around $1150 \mathrm{~ms}$ ( $p<.05$, corrected). This activity extended between 1050 and $1190 \mathrm{~ms}$ ( $p<.001$, uncorrected) (Fig. $2 \mathrm{~A}$ and $\mathrm{B}$ ).

\subsubsection{Alpha frequency band $(8-12 \mathrm{~Hz})$}

Distributed source localization of alpha-range activation revealed that the right occipito-temporal region was more activated ( $p<.05$, corrected) during the verbal-spatial task compared to the verbal task, showing a peak latency of $340 \mathrm{~ms}$. This activity was evident from 330 to $370 \mathrm{~ms}$ ( $p<.001$, uncorrected). A greater oscillatory response was found during the verbal task in left inferior temporal lobe, peaking at around $780 \mathrm{~ms}(p<.05$, corrected). This activity was observed in a time range between 730 and $850 \mathrm{~ms}$ ( $p<.001$, uncorrected). Left occipital region also showed an enhanced alpha oscillatory activity, peaking around $930 \mathrm{~ms}$ $(p<.05)$, that extended between 890 and $960 \mathrm{~ms}(p<.001$, uncorrected) (Fig. 2B).

\subsubsection{Beta frequency band $(13-30 \mathrm{~Hz})$}

Significantly greater oscillatory activity in the verbal-spatial task compared to the verbal task was observed over PPC, bilaterally, peaking at around $180 \mathrm{~ms}$ (left PPC) and $210 \mathrm{~ms}$ (right PPC) $(p<.05$, corrected). Left inferior parietal lobe also showed greater oscillatory activity during the verbal-spatial task, showing a peak latency of $530 \mathrm{~ms}(p<.05$, corrected). These activations lasted from 160 to $220 \mathrm{~ms}$ ( $p<.001$, uncorrected) and between 490 and $540 \mathrm{~ms}$ ( $p<.001$, uncorrected), respectively. $T-F$ analysis also showed a greater activity in sources located in right DLPFC in the verbal-spatial task, peaking at around $310 \mathrm{~ms}(p<.05$, corrected), extending from 290 to $350 \mathrm{~ms}$ ( $p<.001$, uncorrected) (Fig. 2A and B). 
(A)
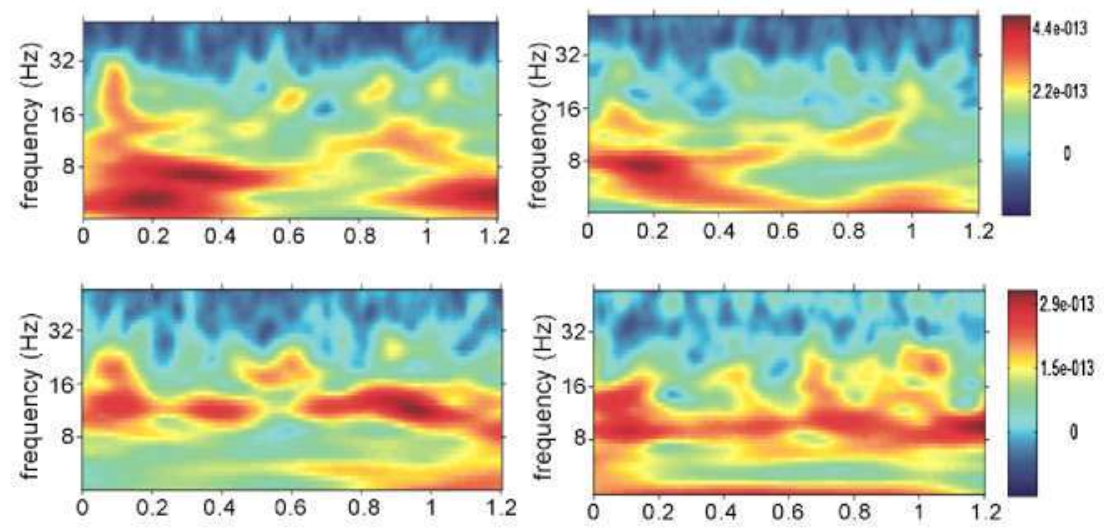

(B)

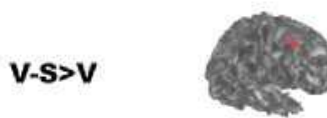

Theta

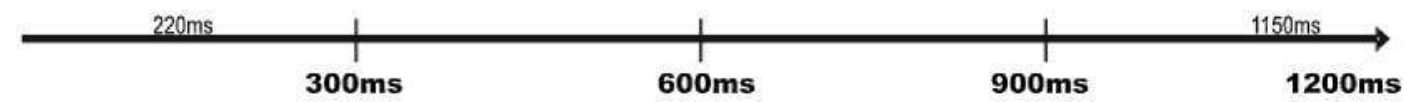

V $>$ V-S

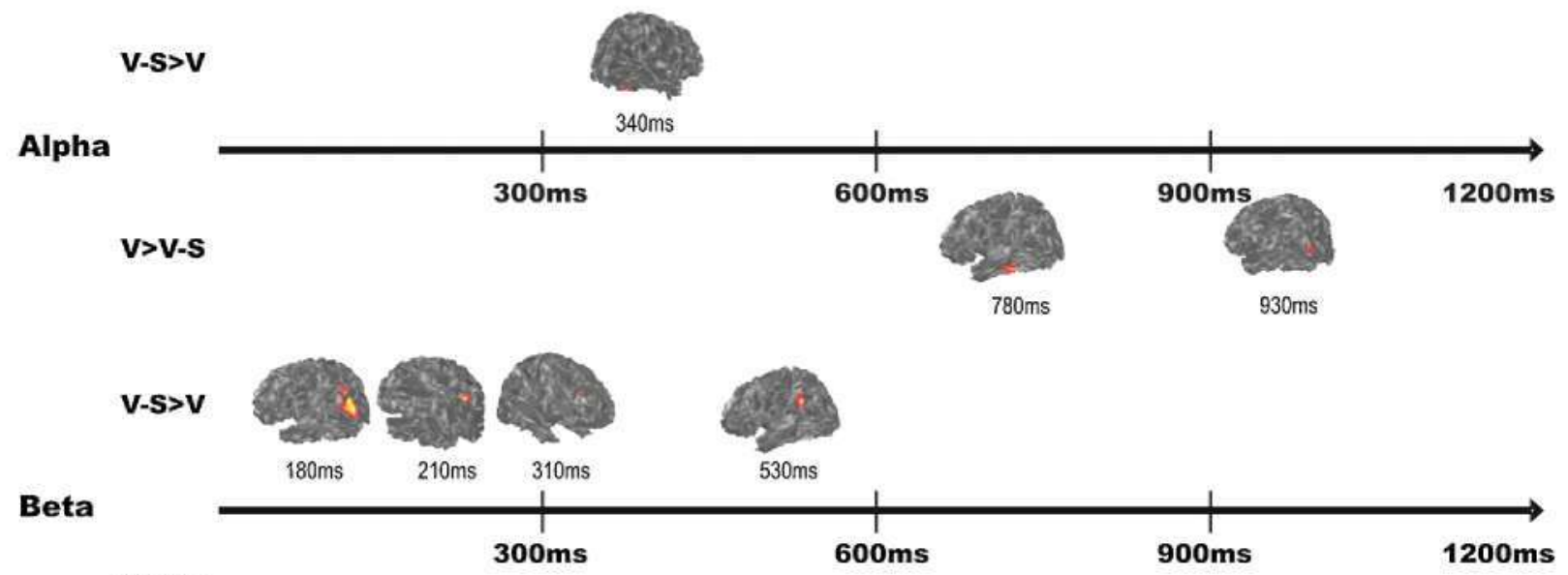

V > V-S

$200 \mathrm{~ms}$
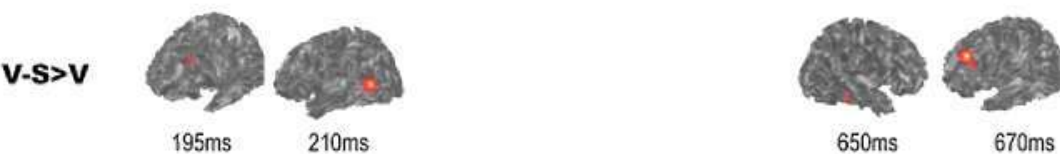

$650 \mathrm{~ms}$

$670 \mathrm{~ms}$

Gamma

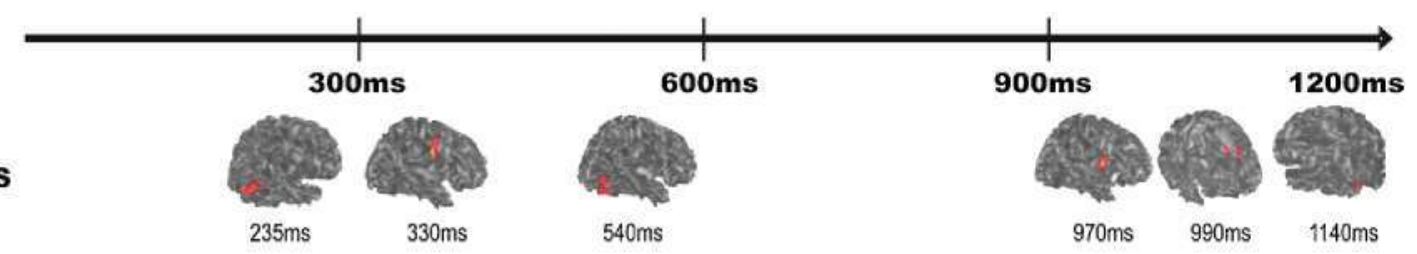

V>V-S

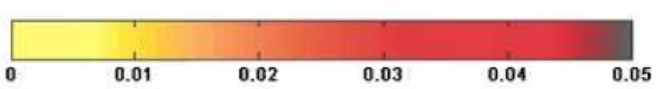

Fig. 2. (A) Grand average time-frequency $(T-F)$ representations, including evoked and induced oscillations, for the two tasks are depicted. $T-F$ plots for a left anterior sensor for both tasks are shown on the upper panel; $T-F$ plots for a left posterior sensor for both tasks are shown on the bottom panel. (B) Shows the result of the group analysis projected onto a tessellated cortical mesh template surface derived from the Montreal Neurological Institute (MNI) phantom brain. The figure depicts sources indicating maximum statistically significant difference in amplitude between tasks in specific time bins for different frequency ranges by means of $p$ values ( $p<.05$ corrected). Only $p$ values exceeding the critical $p$ value of, 05 are shown. Colorbar indicate the $p$ values. 


\subsubsection{Gamma frequency band $(30-50 \mathrm{~Hz})$}

Source differences in gamma band activity were detected in left DLPFC, indicating greater activation in the verbal-spatial task compared to the verbal task ( $p<.05$, corrected). This activity showed a first peak latency of $195 \mathrm{~ms}(p<.05$, corrected), and lasted from 180 to $215 \mathrm{~ms}$ ( $p<.001$, uncorrected). A second significant peak was observed at around $670 \mathrm{~ms}$ ( $p<.05$, corrected), lasting between 660 and $700 \mathrm{~ms}(p<.001$, uncorrected). Topographical distribution of the source estimates for oscillatory activity in gamma band also showed significant greater activation in posterior regions during the verbal-spatial task. Specifically, differences were observed over left and right occipito-temporal regions ( $p<.05$, corrected), peaking at around 210 and $650 \mathrm{~ms}$, respectively. Right premotor cortex and bilateral medial PFC showed significantly greater oscillatory activity in the verbal task as compared to the verbal-spatial task. Activations in premotor cortex peaked at around 330 and $970 \mathrm{~ms}$ $(p<.05$, corrected), and were observed between 315 and $370 \mathrm{~ms}$ and between 960 and $1000 \mathrm{~ms}$ ( $p<.001$, uncorrected). Activity in medial PFC showed a peak latency of $990 \mathrm{~ms}(p<.05$, corrected). and was evident between 970 and $1000 \mathrm{~ms}$ ( $p<.001$, uncorrected). The verbal task was also associated with greater activity over left and right occipital cortex in three different time windows $(p<.05$. corrected), peaking at around $235 \mathrm{~ms}$, and $540 \mathrm{~ms}$ in the right hemisphere, and around $1140 \mathrm{~ms}$ in the left hemisphere (Fig. 2B).

\section{Discussion}

In the present study, we reported the first attempt to study verbal-spatial binding under conditions where only the verbal feature was to be attended (verbal task) - known to produce spontaneous verbal-spatial binding (Campo et al., 2010) - compared to a task where both the verbal and spatial features were attended. The comparison was carried out using with MEG, by contrasting the patterns of neural oscillatory activity in 'classical' frequency bands as a function of whether participants attended and memorized the verbal features only (verbal task) or both verbal and spatial features (verbal-spatial task). The two tasks we compared were identical in terms of their perceptual characteristics, and only differed with respect to the instructions given to participants, resulting in different processing demands. The behavioural results revealed significant and equivalent cross-code binding effects in both tasks, both with respect to accuracy and response latencies. Of interest were any differential patterns of neural activity evidenced between the two tasks.

The results of the oscillatory neural activity showed that verbal-spatial binding relied on partially distinct neuroanatomical substrates when one and both features were attended and encoded. As our behavioural measures indicated binding effects in both tasks. and no differences in terms of accuracy or speed response, we can conclude that differences between tasks in oscillatory activity were due to the requirement to intentionally process both verbal and spatial information classes. It was found that maintenance during the verbal-spatial task was associated with the activation of a dorsal processing stream including DLPFC, premotor areas and $P P C$, mainly during the first half of the retention period. Activity in these areas were found in the theta, beta and gamma frequency ranges. Maintenance during the verbal task was associated with gamma activity in anterior dorsal areas, including premotor cortex and medial PFC. Contrary to the verbal-spatial task, the majority of these activations were observed later in the retention period (i.e. second half). Activity in the occipital and left temporal cortices in gamma and alpha frequency bands were observed during the maintenance period in both tasks.

In sum, differences between tasks were observed in frequency, location and time. Interestingly, oscillatory activity in the theta and beta bands was only observed during the verbal-spatial task. Using the same paradigm, Wu et al. (2007) showed greater oscillatory activity in theta band over frontal sites during intentional maintenance of integrated letter-location features as compared to unintegrated features. Summerfield and Mangels (2005) reported a similar pattern of anterior theta activation during intentional encoding of word-color association as compared to word-only encoding. As results from these studies were based on data analyzed at sensor level, which do not allow a precise localization of the effect, we are not able to compare the anatomical localization (i.e. premotor cortex) of the theta activity observed in our study with that reported in the above mentioned studies. Nonetheless, theta oscillations in anterior areas appear to be a common finding. As pointed by some authors (Deiber et al., 2007; Payne \& Kounios, 2009: Sauseng, Hoppe, Klimesch. Gerloff, \& Hummel, 2007) the amplitude of frontal theta activity depends on the attentional leve] required to deal with the task rather than on the amount of information being manipulated. While task difficulty, and therefore mental effort, is "intrinsically linked to the highest memory load" (Deiber et al., 2007), the finding, in our data, of equivalent behavioural binding effects irrespective of whether participants encoded one or both features, could then be considered as reflecting different task demands - if we assumed that the intentional processing of the consonants and locations in the verbal-spatial task may have required the allocation of more cognitive resources - but equivalent memory loads. Thus, the greater oscillatory activity observed over premotor areas in the verbal-spatial task is consistent with previous findings that linked central executive functions to theta oscillations in anterior sites during the retention period of a WM task (Deiber et al., 2007; Schack, Klimesch, \& Sauseng, 2005).

When considering differences in the brain regions activated in both tasks, it appears that activity in PFC and PPC was mediated by the manipulation of processing demands. On the one hand, enhanced activity in posterior regions requiring intentional control has been observed in previous studies (Dove et al., 2008). Focusing attention or intentional processing have been shown to increase activation in modality specific regions (Ranganath, DeGutis, \& D'Esposito, 2004). Thus, the increased oscillatory activity in beta band in PPC during the verbal-spatial task could be reflecting the intentional processing of spatial locations in this task (Corbetta \& Shulman, 2002). Alternatively, this enhancement could indicate that more attentional resources were deployed in the verbal-spatial task than in the verbal task. Interestingly, a prior study (Deiber et al., 2007) described a higher parietal beta activity for a demanding WM task, which was interpreted as reflecting enhanced attention. The time window in which we observed the effect is consistent with the so-called N2pc (an ERP component) the amplitude of which is considered to reflect the attentional requirements of performing a task (Luck \& Hillyard, 1994). Interestingly, recent evidence shows that the amplitude of N2pc was greater in a feature-location binding condition as compared to a simple feature detection condition (Hyun, Woodman, \& Luck, 2009). On the other hand, prefrontal gamma band oscillatory activity has been related to attention driven top-down processes (Cho, Konecky, \& Carter, 2006; Engel, Fries, \& Singer, 2001; Fan et al., 2007; Klimesch, Freunbergerd, \& Sauseng, 2010), and may also extend to neural activity in the beta frequency range (Klimesch et al., 2010). While activity in frontal areas was observed in both tasks, the time course of the frontal beta and gamma activity during the verbal-spatial task is consistent with findings from a recent study exploring the frequency components of an executive control network (Fan et al., 2007). Specifically, it was shown that the executive attentional network was associated with a strong early increase in gamma band power, along with beta band, during the 100-300 ms period after target onset. Enhancement of early anterior components of the ERP (140-160 ms) has also been reported 
in an spatial WM task (Awh, Anllo-Vento, \& Hillyard, 2000). On this basis, the distinct patterns of activity we observed in the beta and gamma bands over anterior PFC might reflect differences in the strategic/attentional control processes between tasks. Addjtionally, the topographical distribution of frontal beta and gamma activity specifically observed during the verbal-spatial task is also consistent with several proposals about the crucial role played by lateral PFC in strategic recoding (Bor, Cumming, Scott, \& Owen, 2004; Bor et al., 2003; Bor \& Owen, 2007; Savage et al., 2001) and with functional neuroanatomical findings of previous neuroimaging studies comparing controlled and incidental memory processes (Buckner \& Koutstaal, 1998; Buckner et al., 1995; Chiu et al., 2006; Fletcher et al., 2001; Hall, Gjedde, \& Kupers, 2008; Kapur et al., 1996; Koechlin, Basso, Pietrini, Panzer, \& Grafman, 1999; Noldy et al., 1990; Reber et al., 2003; Rugg et al., 1997; Schott et al., 2002, 2005), which collectively indicated a greater activation of DLPFC during controlled memory. In contrast, the medial PFC (activated late in the retention period in the verbal task) has been associated with spontaneous object and object-location memory in rats (Ennaceur, Neave, \& Aggleton, 1997). Considered together, the greater engagement of a dorsal fronto-parietal attentional network (Corbetta \& Shulman, 2002) in the task in which both features were required to be intentionally processed might reflect the allocation of spatial attention to locations held in WM (Awh et al., 2000), or the greater executive/attentional resources that were necessary in order to accomplish the task (Chun \& TurkBrowne, 2007). These two alternatives are not mutually exclusive as selective spatial attention is at the core of models invoking cross-modal influences of spatial attention in multisensory integration (Corbetta \& Shulman, 2002; Macaluso \& Driver, 2005; Marois \& Ivanoff, 2005; Senkowski, Talsma, Herrmann, \& Woldorff, 2005).

One might tentatively propose that participants in the verbal-spatial task may have used binding as a strategy for making more efficient use of short-term memory by recoding information. However, this interpretation should be reconciled with recent findings (Morey, 2009; Wheeler \& Treisman, 2002) suggesting that verbal and visuospatial features can be simultaneously maintained in their respective modality-specific buffers or in a domain-general store, depending on what information is necessary to complete the task. In the current experiment, we are unable to exclude that letter-location binding was also implicit in the verbal-spatial task.

Oscillatory activity in alpha and gamma bands were observed in similar brain regions, specifically occipital and left temporal cortices, across the verbal and verbal-spatial tasks. Colocalized neural responses in posterior brain regions comparing implicit and explicit have been previously shown. This finding has been suggested to "reflect perceptual processes common to the two forms of memory" (Turk-Browne, Yi, \& Chun, 2006). In our case, occipital and temporal regions could be signaling processing of the verbal component of the stimuli, which is common for both tasks.

In summary, the present study provides, for the first time, evidence that behaviourally equivalent binding effects yielded by single and dual feature encoding conditions rely on different neuroanatomical and neural oscillatory correlates. Our results show a complex pattern of frequencies, neural generators and timing. Thus, the specific T-F patterns and different neural generators found during the retention period of each task provide evidence for the distinction of the processes supporting intentional and unintentional letter-location binding in WM. Since both tasks were identical in all respects except instructions, we propose that enhanced activation of an anterior-posterior dorsal network observed in the verbal-spatial task reflected the greater allocation of attentional resources to the intentional processing of both verbal and spatial features in this task (Chun \& Turk-Browne, 2007).

\section{Acknowledgements}

This work was supported by a research grant from the Spanish Ministry of Education and Science (Grant SE]2006-14571) to Pablo Campo, by a research grant from the UK's Economic and Social Research Council (Grant RES-062-23-0241) and a Ramon y Cajal Fellowship from the Spanish Ministry of Science and Innovation (RYC-2007-00701) awarded to Fabrice Parmentier, and partially supported by a Grant from the Comunidad Autónoma de Madrid (Madr.IB S-SAL-0312-2006).

\section{References}

Alvarez, G. A., \& Cavanagh, P. (2004). The capacity of visual short-term memory is set botli by visual information load and by numbet of objects. Psychological Science. 15(2), 106-111.

Allen, R. J., Baddeley, A, D., \& Hitch, G. J. (2006). Is the binding of visual features in working memory resource-demanding? journat of Experimentar Psycholoyy. General, 135(2), 298-313.

Awli, E. Anllo-Vento, L., \& Hillyard, S, A, (2000). The role of spatial selective attention in working memory for locations: Evidence from event-related potent ials. Jound of Cognitive Neurosience, 12(5), 840-847.

Baddeley. A. (2000). The episodic butfer: A new component of wotking memory? Trends in Cognitive Sciences, 4(11), 417-42.3

Bays, P. M., \& Husain, M. (2008), Dynamic shitts of limited working memory resources in human vision. Science, 321(5890), 851-854.

Bodelon. C., Fallah M. \& Reynolds, J. H. (2007). Temporal resolution for the perception of features and conjunct ions. The fotmol of Neurosctence, 27(4), 725-730.

Bor, D., Cumming, N., Scott, C. E., \& owen, A. M. (2004). Prefrontal cortical involvement in vetbal encoding strategies. The European journat of Neuroscience, 19, 12) $3365-3370$.

Bor, D., Duncan. J., Wiseman, R. J., \& (uwen, A. M. (2003). Encoding strategies dissociate preftontal activity from wotking memory demand. Neuron, 37, 361-367.

Bor, D., \& owen, A. M. (2007). A common prefrontal-parietal network for mnemonic and mathematical recoding strategies within working memory. Cerebral Cortex $17.778-786$.

Bouhamidi, A., \& Jbilou, K. (2007). Sylvester Tikhonov-regularization methods in image restocation, Jotmal of Computationat and Applied Mathematcs, 206, 86-98.

Buckmet, R. L., \& Koutstad, W. (1998). Functional neuroimaging studies of encoding. priming, and explicit memory retrieval. Procedings of the National Academy of Sciences of the united States of America, 95(3), 891-898.

Buckner, R. L., Petersen, S. E., Ojemann, J. G., Miezin, F. M., Squire, L. R. \& Raichle, M.E (1995). Functional anatomical studies of explicit and implicit memory retrieval tasks. Joumal of Neurosctence, 15, 12-29.

Campo, P., Maestu, F., Capilla, A., Morales, M., Fernandez, S., del Rio, D., et al. (2008) Temporal dynamics of pariet al activity duting word-location bi inding. Netiropsychology, 22(1), 85-99.

Campo, P., Maestu, F., Ortiz, T., Capilla, A., Santiuste, M., Fernandez, A., et al. (2005) Time modulated pretrontal and parietal activity during the maintenance of integrated information as revealed by magnetoencephalography. Cerebral cortex, 15(2), 123-130

Campo, P., Poch, C, Patmentiet, F. B., Motatti, S., Elsley, J. V., Castellanos, N. P., et al, (2010). Oscillatory activity in prefrontal and posterior regions during implicit letter-location binding. Neuromaye, 49, 2807-2815.

Cometta, M., \& Shulman, G. L. (2002). Control of goal-directed and stimulus-driven attention in the brain. Nature Reviews. Neuroscience, 3(3), 201-215.

Cowan, $N_{*}$ (2001). The magical number 4 in short-term memory: A reconsideration of mental storage capacity. The Behavioural and Brain Sciences, 24(1), 87-114 discussion 114-185)

Cowan, N., Saults, J. S., \& Morey, C. C. (2006). Development of wotking memory to verbal-spatial associat ions. Joumal of Memory and Language, 55(2), 274-289.

Chiu, M. J., Hua, M. S, Chen, T. F., Hwu, H. G., Kao, C. H., \& Chell, C. H. (2006). Brail responses of explicit and implicit memory: An event-related potential study. Newroport, $77,1483-1486$

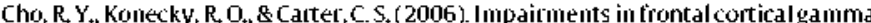
synchrony and cognitive control in schizophrenia. Proceedings of the National Academy of Sciences of the United States of America, 103, 19878-19883.

Chun, M. M., \& Turk-Browne, N. B. (2007). Interactions between attention and memory. Current Opinion in Neumbiology, 17(2), 177-184

Deiber, M. P., Missonniec, P., Bettrand, O. Gold, G., Fazio-Costa, L., Ibanez, V., et al, (2007). Distinction between perceptual and attentional processing in working memory tasks: A study of phase-locked and induced oscillatory brain dynamics. Jotmal of Coynitive Netiroscience, $19(1), 158-172$

Delvenne, J. F., Braithwaite, J. J., \& Humphreys, G. W. (2002). Capacity limits in visual shot term memory tor local otientations. Current Psycholong of Coynition, 21 . $681-690$.

Dove, A., Manly, T., Epstein, R., \& Owen, A. M. (2008). The engagement of mid ventcolateral pefrontal cortex and postecior braim regions in intentional cognitive activity. Human Brain Mapping, 29, 107-119.

Elsley, J. V. \& Parmentiet, F. B. (2009). Is vetbal-spatial binding in working memoty impaited by a concutrent memory load? The Quarterly journat of Experimenta Psychology (Colchester), 62(9), 1696-1705. 
Engel, A. K., Fries, P., \& Singer, W. (2001). Dynamic predictions: Oscillations and synchiony in top-down processing. Natire Reviews. Netiroscience, 2(10), 704-716.

Ennaceut, A., Neave, N., \& Aggleton, J. P. (1997). Spontaneous object recognit ion and object location memory in rats: The effects of lesions in the cingulate cortices, the medial preficontal cortex, the cingulum bundle and the fornix, Experimentat Brain Research, 113(3), 509-519.

Ericsson, K. A., Chase, W. G., \& Faloon, S. (1980). Acquisition of a memory skill. Science, 208, 1181-1182.

Eriksen, C. W., Yeh, Y. Y. (1985). Allocation of attention in the visual field. Jormal of Experimental Psychology. Human Perception and Perfornance, 11(5), 583-597.

Fan, J., Byrne, J., Worden, M. S. Guise, K. G., McCandliss, B. D., Fossella, J., et al. $(2007)$. The relation of brain oscillations to attentional networks. The Journal of Netirosicience, $27(23), 6197-6206$.

Fernandez, G., \& Tendolkar, I. (2001). Integrated brain activity in medial temporal and prefrontal areas predicts subsequent memory performance: Human declarative memoty formation at the system level, Brain Research Buifetin, 55(1), 1-9.

Filbey, F. M., Holroyd, T., Carver, F., Sunderland, T., Cohen, R. M. (2005). A magnetoencephalography spatiotemporal analysis of neural activities ducing teature bindiug Neuroreport 16 (16), 1747-1752.

Fletcher, P. C., Zafiris, O., Honey, R., Fink, G., Frith, C. D., \& Zilles, K. (2001). Regional brain act ivity associated with intentional and incidental sequence leaching. Neuroimage, 13,665.

Friedman-Hill, S. R., Robertson, L. C., \& Treisman, A. (1995). Parietal contributions to visual featuce binding: Evidence ftom a patient witl bilateral lesions. Science. $2695225), 853-855$

Gray. C. M. (1999). The temporal correlation hypothesis of visual teature integration: Still alive and well. Neuron, 24(1), 31-47, 11-125.

Hall, N. M. Gijedde, A. \& Kupers, R. (2008). Neural mechanisms of voluntary and involuntary recall: A PET study. Behovioural Brain Research, 25, 261-272.

Huang, M. X., Mosher, J. C. \& Leahy, R. M. (1999). A sensor-weighted overlappingsphere liead model and exhaustive head model comparison for MEG. Physics in Medicine and Bloloyy, 44, 670-678.

Hyun, J., Woodman, G. F., \& Luck, S. J. (2009). The role of attent ion in the binding of surtace teatures to locations. Visual Commition, 17, 10-24.

Jensen, 0. . \& Vanni, S. (2002). A new method to identify multiple sources of oscillatory activity from magnetoencephalographic data. Newroimage, 15(3), 568-574.

Kahmeman, D., Treisman, A.\& Gibbs, B. J. (1992). The reviewing of object files: Objectspecific integration of information. Cognizive Psychology, 24(2), 175-219.

Kapur, S., Tulving, E, Cabeza, R. McIntosli, A, R., Houle, S., \& Craik, F. I. (1996). The neural correlates of intentional learning of vebal materials: A PET study in humans. Cognitive Brain Research, 4, 243-249.

Klimesch, W. Freunbergerd, R, \& Sauseng, P. (2010). Oscillatory mechanisms of process binding in memory. Neuroscience E' Biobehavioral Reviews, 34, 1002-1014.

Koechlin, E, Basso, G. Pietrini, P., Panzer, S., \& Grafiman, J. (1999). The wole of the antetior ptefront al cortex in human cognition. Nature, 399, 148-151.

Kubler, A., Murphy, K., Kaufman, J., Stein, E. A., Baravan, H. (2003). Co-ordination within and between verbal and visuos patial wotking memory: Network moduIation and anterior frontal recruit ment. Netromage, 20(2), 1298-1308.

Lekell, F., Marczewski, P., Van der Linden, M., Collette, F., Degueldre, C., Del Fiore, G., et al, (2002). Effects of incident al and intentional featu re bind ing on recongition: A behavioural and PET activation study. Neuropsyciologia, 40(2), 131-144.

Luck, D., Danion, J. M., Marter, C, Pham, B. T., Gounot, D., \& Foucher, J. (2010). The right parahippocampal gyrus contributes to the formation and maintenance of bound information in working memory. Brain and cognition, 72(2), 255-263.

Luck, D., Foucher, J. R., Offerlin-Meyer, I., Lepage, M., Danion, J. M. (2008). Assessment of single and bound features in a working memory task in schizophrenia. Schizophremia Research, 100(1-3), 153-160.

Luck, S. J., \& Hillyard, S. A. (1994). Electrophysiological correlates of feature analysis du ring visual seatch. Psychophysiotogy, 31(3), 291-308.

Luck, S. J., \& Vogel, E. K. (1997). The capacity of visual working memory for features and conjunctions. Nature, 390(6657), 279-281.

Macaluso, E., \& Driver, J. (2005). Multisensory spatial interactions: A window onto functional integration in the human brain. Trends in Neurosciences, 28(5), 264-271.

Mallat, S. (1998). A wavelet tour of signal processing. San Diego: Academ ic Press.

Maris, E., \& Oostenveld, R. (2007). Nonparametric statistical testing of EEC;- and MEG-data. Jotimal of Netirosclence Methods, 164, 177-190.

Marois, R., \& Ivanoff, J. (2005). Capacity limits of informat ion processing in the brain. Trends in Cognitive Stiences, $9(6), 296-305$.

Maybery, M. T., Clissa, P. I., Parmentier, F. B., Leung, D., Harsa, G., Fox, A. M., et al. (2009). Binding of verbal and spatial features in auditory working memory. joumal of Mernory and Language, 61, 112-133.

Miller, $G . A_{4}(1956)$. The magical number seven plus or minus two: Some limits on our capacity for processing information. Psychology Review, 63(2), 81-97.

Mitchell, K. J., Johisson, M. K., Raye, C L., \& D'Esposito, M. (2000). TMRI evidence of age-related hippocampal dysfunction in feature binding in working memory. Brain Research. Cognitive Brain Research, 10(1-2), 197-206.

Mitroft, S. R, \& Alvatez, G. A. (2007), Space and time, not sutface teatures, guide object persistence. Psychonomic Buffetin \& Review, 14(6), 1199-1204.

Moratti, S., Rubio, G. Campo, P., Keil, A., \&Ottiz, T. (2008), Hypofunction of tight temporoparietal cortex during emotional arousal in depression. Archives of General Psychiatisy, 65(5), 532-541

Morey, C.C. (2009), Integrated cross-domain object storage in working memory: Evidence from a verbal-spatial memory task. The Quorterly Joumal of Experimentol Psychology (Colchester), 1-17.
Noldy, N. E., Stelmack, R. M., \& Campbell, K. B. (1990). Event-related potentials and recognition memory tor pictures and words: The effects of intent ional and incidental learning. Psychophysiology. 27(4), 417-428.

Oraven K. M., Downing. P. E., Kanwisher, N. (1999). AMRI evidence for objects as the units of attentional selection. Nature, 401(6753), 584-587.

oberauer, K. \& Vockenberg. K. (2009). Updating of working memory: Lingering bindings. The Quarterly joumal of Experimental Psychology (Colchester), 62(5), 967-987.

Palva, S., Monto, S., \& Palva, J. M. (2010). Graph properties of synchronized cortical metwotks during visual wotking memory maintenance. Netrormaye, 49. $3257-3268$.

Payne, L., \& Kounios, J. (2009). Coherent oscillatory networks supporting short-term memony retention. Brain Research, 1247, 126-132.

Prabhakaran, V., Narayanan, K., Zhao, Z., \& Gabrieli, J. D. (2000). Integration of diverse information in working memory within the frontal lobe. Natire Netrosience, 3(1), 85-90.

Rainer, G., Asaad, W. F., Miller, E. K. (1998a). Memory fields of neurons in the primate ptefirontal cortex. Proceedings of the National Academy of Sciences of the United States of America, 95.25) 15008-15013.

Rainer, G., Asad, W. F., \& Miller, E. K. (1998b). Selective representation of relevant information by neu rons in the ptimate preftontal contex. Nature, 393(6685). $577-579$.

Ranganath, C., DeGut is, J.. \& D'Esposito. M. (2004). Category-specitic modulation of interior temporal activity du ring working memory encoding and maintenance. Cognitive Brain Research, 20,37-45

Rao, S. C, Rainet, G., \& Miller, E. K. (1997). Integration of what and whete in the primate prefrontal cortex. Science, $276(5313), 821-824$.

Reber, P. J., Gitelman, D. R., Parrish, T. B., \& Mesulam, M. M. (2003). Dissociatíng explicit and implicit category knowledge with IMRI. Journat of Coynitive Netiroscience, $15,574-583$.

Reber, P. J., Siwiec, R. M., Gitelman, D. R. Patrish, T. B., Mesulam, M. M., Paller, K. A. et al. (2002). Neural cortelates of successtul encoding identified using functional magnetic resonance imaging. The Joumal of Neuroscience, 22(21) 9541-9548.

Rugg, M. D., Fletcher, P. C., Frith, C. D., Frackowiak, R. S., \& Dolan, R. J. (1997). Brain regions supporting intentional and incidental memory: A PET study. Neuroreport, 8(5) 1283-1287.

Rugg, M. D., Mark, R. E., Walla, P., Schloerscheidt, A. M., Astrid, M., Birch, C. S., et al. (1998). Dissociation of the neural correlates of implicit and explicit memory. Nature, 392, 595-598

Russeler, J., Hennighausen, E., Munte, T. F., \& Rosler, F. (2003). Differences in incidental and intentional learning of sensotimotor sequences as revealed by event-related brain potentìals. Brain Research, Cognitive Brain Research, 15(2), $116-126$.

Saito, D. N., Yoshimura, K, Kochiyama, T., Okada, T., Honda, M., \& Sadato, N. (2005). Cross-modal binding and activated attentional networks during audiovisual speech integration: A functional MRI study. Cerebral Cortex, 15(11). $1750-1760$.

Sauseng, P., Hoppe, J., Klimesch, W., Gerloff, C., \& Hummel, F. C. (2007). Dissociation of sustained attention from central executive tunctions: Local activity and interregional connectivity in the theta range. The European journal of Neurosience, 25(2), 587-593.

Savage, C. R., Deckersbach, T., Heckers, S, Wagner, A, D. Schacter, D. L, Alpett, N. M., et al. (2001). Prefrontal regions supporting spontaneous and directed application of vetbal learning strategies: Evidence trom PET, Brain, 124, $219-231$.

Schack, B., Klimesch, W., \& Sauseng, P. (2005). Phase sync hronization between theta and upper alpha oscillations in a wotking memoty task. International journat of Psychoplysiology, 57(2), 105-114.

Sclineider, W., Escliman, A., \& Zuccoloto, A. (2002). E-Prime reference gutide, Pittsburgh: Psychology Software Tools Inc.

Schott, B., Richardson-Klavehn, A., Heinze, H. J., \& Duzel, E. (2002). Perceptual priming versus explicit memory: Dissociable neutal correlates at encoding. journat of Cognitive Neuroscience, 14(4), 578-592.

Schott, B. H., Henson, R, N., Richardson-Klavelin, $A_{*}$, Becker, $C_{*}$ Thoma, V., Heinze, H. J. et al. (2005). Redefining implicit and explicit memory: The functional neuroanatomy of priming. remembering, and control of retrieval. Proceedings of the Natlonal Academy of Sciences of the united States of America, 102(4). $1257-1262$.

Senkowski, D. Talsma, D., Herrmann, C S., \& Woldorff, M. G. (2005) Multisensory processing and oscillatory gamma responses: Effects of spatial selective attention. Experimental Brain Research, 166(3-4), 411-426.

Simon-Tlımas, E. R, Brodsky. K., Willing, C., Simha, R, \& Kmight, R. T. (2003). Distributed neural activity ducing object, spatial and integrated processing in humans. Brain Researd. Cognitive Bram Research, 16(3), 457-467.

Simon, H. A, (1974). How big is a clunk? Sclence, 183, 482-488.

Summerfield, C.. \& Mangels, J. A. (2005), Coherent theta-band EEG activity predicts item-context binding duting encoding. Neuroimage, 24(3), 692-703.

Tallon-Baudry, $C_{*}$ Bettrand, O. Delpuecli, C., \& Permiel, J. (1997), Oscillatorygammaband $(30-70 \mathrm{~Hz})$ activity induced by a visual search task in humans. The journat of Netiroscience, 17, 722-734.

Todd, J. J. \& Marois, R. (2004). Capacity limit of visual short-term memory in human poste rior parietal cortex. Narme, 428(6984), 751-754

Tutk-Btowne, N. B., Yi, D. J. \& Chum, M. M. (2006). Linking implicit and explicit memory: Common encoding factors and shared representations. Neuron, 49(6), 917-927. 
Vogel, E. K., \& Machizawa, M. G. (2004). Neural activity predicts individual differences in visual working memory capacity. Natlite, 428(6984). 748-751.

Vogel, E, K., Woodman, G. F., \& Luck, S.J. (2001). Storage of teatures, conjunctions and objects in visual working memory. Jounal of Experimental Psychology. Human Perception and Performance, 27(1), 92-114.

Voss, J. L., \& Paller, K. A. (2008). Brain substrates of implicit and explicit memory: The importance of concurrently acquiced neural signals of both memory types. Netiropsychotogia, 46, 3021-3029.

Wagner, A. D. (1999). Working memory contributions to human learning and remembering. Neuron, 22(1), 19-22.

Wheeler, M. E., \& Treisman, A. M. (2002), Binding in short-term visual memory. Jounal of Experimental Psydiology. General, $133(1), 48-64$.
Widmann A, Giruber, T. Kujala, T., Tervaniemi, M. \& Schroger, E. (2007). Binding symbols and sounds: Evidence from event-related oscillatory gamma-band activity. Cerebrai Cortex, 17(11), 2696-2702.

Wolfe, J. M., Yu, K. P., Stewart, M. I., Shorter, A. D., Friedman-Hill, S. R. \& Cave, K $R_{4}(1990)$. Limitations on the parallel guidance of visual search: Color $\backslash$ color and orientation $\backslash$ orientation conjunctions. Joumal of Experimental Psychology. Human Perception and Performance, $16(4), 879-892$.

Wu, X., Chen, X, Li, Z, Han, S., \& Zliang, D. (2007), Binding of vetbal and spatial information in human working memory involves large-scale neural synchronization at theta frequency. Neuroimage, 35(4), 1654-1662.

Zliang. $W_{+}$\& Luck, $S_{+} J_{+}(2008)$. Discrete fixed-resolution representations in visual working memory. Nature, 453(7192), 233-235. 